\title{
A elevação da qualidade da pós-graduação: uma proposta da Universidade Federal do Amazonas
}

\section{Improving the quality of graduate education: a proposal at the Federal University of Amazonas}

\section{Mejorar la calidad de la educación de posgrado: una propuesta de la Universidad Federal del Amazonas}

Selma Suely Baçal de Oliveira, doutora em Educação pela Faculdade de Educação da Universidade de São Paulo (USP) e professora associada nivel 2 da Universidade Federal do Amazonas (Ufam). Endereço: Rua Luíz Venzon, 18 - Zumbi do Palmares III. CEP: 69084-055 - Manaus, AM. Telefone: (092) 9112-8030. E-mail: selmabacal@Ufam.edu.br.

Emídio Cantídio de Oliveira Filho, doutor em Ciência do Solo pela University of California, Davis (UCDAVIS), Estados Unidos, e professor adjunto IV da Universidade Federal Rural de Pernambuco. Endereço: Universidade Federal Rural de Pernambuco. Rua Dom Manoel de Medeiros, s/n - Dois Irmãos. CEP: 52171-900 - Recife, PE. Telefone: (81) 3320-6233. Ramal: 6220. E-mail: emidio. cantidio@gmail.com.

Arone do Nascimento Bentes, mestre em Educação pela Universidade Federal do Amazonas (Ufam) e professor efetivo do Instituto Federal de Educação, Ciência e Tecnologia do Amazonas (Ifam). Endereço: Rua Hawaí n³ 3, Conjunto Residencial Ponta Negra - Nova Esperança. CEP:69037-340 - Manaus, AM. Telefones: (092) 3656-1139 / 8179-9958. E-mail:aronebentes@ifam.edu.br. 


\section{Resumo}

O presente artigo tem como tema a gestão do ensino superior público. Constitui uma análise de iniciativa da Universidade Federal do Amazonas para a elevação da qualidade nos programas de pósgraduação que oferece. O texto avalia, no âmbito de suas linhas, a proposta do Programa de Apoio à Consolidação e ao Avanço da Qualidade da Pós-Graduação da Universidade Federal do Amazonas - PACPG/ Ufam, que, em linhas gerais, estabeleceu como meta a conquista da excelência acadêmica da pós-graduação da Ufam. Trata da concepção de ensino superior e da administração dessa esfera do ensino público federal como catalisadora de uma cultura institucional cujos resultados sejam ricos em eficácia e eficiência acadêmicas.

Palavras-chave: Cultura Institucional. Ensino Superior. Qualidade. PósGraduação. Assimetrias Regionais.

\section{Abstract}

This article focuses on Public Higher Education Management. It provides an analysis of an initiative of the Federal University of Amazonas to increase the quality of graduate program offerings. The paper assesses the proposed Program to Support and Consolidation the Advancement of the Quality of Graduate Study at the Federal University of Amazonas - PACPG/UFAM. The said Program, in general, establishes the goal of achieving the academic excellence of graduate study at UFAM. The article deals with the conception of Higher Education and of the administration of this federal sphere of public education as a catalyst for an institutional culture whose results are rich in academic effectiveness and efficiency.

Keywords: Institutional Culture. Higher Education. Graduate Study. Regional Symmetries.

\section{Resumen}

Este artículo trata de la gestión de la Educación Superior Pública. Es un análisis de una iniciativa de la Universidad Federal de Amazonas 
para mejorar la calidad de los programas de posgrado que ofrece. El documento analiza la propuesta del Programa de Apoyo a la Consolidación y Promoción de la Calidadad del Posgrado de la Universidad Federal de Amazonas - PACPG/UFAM que, en general, fijó como su objetivo alcanzar la excelencia académia. Trata de la concepción de educación superior y de la administración de este sector de la enseñanza pública federal como catalizadora de una cultura institucional cuyos resultados sean ricos en eficacia e eficiencia académica.

Palabras clave: Cultura Institucional. Educación Superior. Calidad. Posgrado. Asimetrías Regionales.

\section{Introdução}

É possivel antever, sobre o debate a respeito do ensino superior no Brasil, um conjunto de ideias cuja abordagem liga o tema da universidade ou da malha universitária existente no País a um projeto de desenvolvimento social comprometido com as reformulações por que passam as sociedades no que diz respeito as suas demandas por educação, por formação em nível de pós-graduação.

Tal conjunto de ideias se configura na premissa de que as instituições sociais responsáveis pela difusão do conhecimento, historicamente, têm uma missão social profundamente enraizada na construção desse conhecimento; na elaboração de instrumentos para a compreensão da natureza das estruturas das classes sociais; na formação de contingente responsável pelo que a faz difusora e caixa de ressonância do saber crítico: a pesquisa, o ensino, a extensão.

Essa abordagem, profundamente procedente e pródiga nos embasamentos teóricos, chama atenção para os resultados acadêmicos e sua relação com a qualidade dos serviços prestados pela universidade, no que diz respeito aos procedimentos que envolvem justamente a ação de ensino, pesquisa e extensão. Esse pensamento ampliou a reflexão sobre o papel funcional das universidades, que, por um lado, integram um aparato ideológico muito significativo, de forte atuação na tradição 
política e econômica, e que, por outro, constituem efetivo espaço de atividades acadêmicas ligadas ao projeto de sociedade mais inclusiva, em que a construção do pensamento leve a práticas que, de fato, assegurem a convivência e garantam direitos civis.

O histórico brasileiro de dependência econômico-financeira constitui um tema inevitável nessa discussão. É possível ver por meio dele as consequências do desenvolvimento desigual e segregacionista vivido pela Nação brasileira. As décadas de 1960, 1970 e 1980 são bem significativas nesse sentido; constituem um tempo em que a universidade assumiu postura combativa e lançou mão de sua natureza formadora para ampliar o debate ideológico e a formação humana mais atrelada à natureza político-econômica dos inúmeros movimentos que, de alguma forma, protagonizavam os cenários nos finais dos anos 70 e em praticamente toda a década de 80 do século passado.

Nos anos 90, os desdobramentos sobre a necessidade de revisão do aparato legal que regulava o processo de ensino e aprendizagem culminaram na aprovação da nova Lei de Diretrizes e Bases da Educação Nacional, a LDB, Lei n 9.394/96, de 20 de dezembro de 1996, sancionada pelo então Presidente da República, Fernando Henrique Cardoso. A referida lei tornou-se o marco educacional dessa década, pois, no que concerne ao ensino superior, permitiu a oferta de vagas pela iniciativa privada ao contingente fora da universidade pública devido ao limitado número de vagas oferecidas pelas instituições mantidas pelo governo. Daí seguiram os programas de financiamentos do Estado, que transferiam recursos públicos para o setor privado a fim de que este assumisse o ensino superior de quem não entrara para a universidade pública.

Essa discussão se faz necessária a fim de explicitarmos um aspecto, se não infértil nesse contexto ideológico, pouco explorado com o rigor metodológico necessário: a aferição da qualidade dos serviços de formação que as universidades oferecem. Sem menosprezar tão rica e procedente visão do ensino superior, essa compreensão nos remete à faceta que irá estruturar a presente exposição: a de que as ações da universidade pública, embora marcadas indelevelmente pelo 
histórico caráter político-ideológico, podem ter padrões de qualidade bem definidos; e que os conceitos de efetividade e eficiência podem estar atrelados a um novo projeto de desenvolvimento da universidade pública, responsável pela geração de conhecimento, pela propagação de culturas, pela operacionalização da pesquisa aplicada, pela produção de tecnologias, produtos e processos e seus benefícios para a sociedade que a financia.

Trataremos aqui de uma experiência de elevação da qualidade dos cursos de pós-graduação de uma universidade pública, os quais configuram conquistas bastante significativas de um período específico que deve servir como alicerce para novos avanços.

Intencionamos tratar o tema da qualidade nos serviços da pósgraduação na Região Norte tendo por base a iniciativa da Universidade Federal do Amazonas sob a ótica do desenvolvimento de uma cultura institucional. É o institucional que primeiramente nos chama atenção, porque sua organização é responsável pelo desenvolvimento de uma cultura elaborada institucionalmente, o que excede a mera aplicação momentânea conjuntural de políticas de gestão. A esse respeito, assim se pronunciam Ferretti e Silva Júnior (2004):

\footnotetext{
A discussão sobre a natureza institucional da escola e sua especificidade tem o mesmo itinerário da discussão da natureza institucional e a especificidade de todas as instituiç̧ões, que, como o próprio substantivo indica, instituem a sociedade em determinado período histórico. Em nosso caso, a modernidade. Instituir a sociedade significa produzir traços culturais que dão unidade às relações sociais (...). Isso nos leva a buscar a origem do institucional, para bem entendermos tal dimensão na escola, ela também uma instituição da modernidade (p. 49).
}

A citação dá uma ideia do papel institucional na cadeia que se estabelece para a formação de uma cultura acadêmica. A universidade, como agente social, contribui efetivamente para a manutenção e regulação do pacto social de um determinado momento histórico, além de, obviamente, socializar o conhecimento acumulado pela humanidade e trabalhar para que tal conhecimento exerça influência benfazeja na rotina e no modo de pensar dos indivíduos e seus pares. Esse devir 
constitui a gênese de uma identidade institucional: o institucional nasce e deve dar à luz uma organização tal que dela derive uma cultura acadêmica.

\section{A pós-graduação na Região Norte do Brasil}

A fim de tratar da realidade do estado do Amazonas, entendemos importante abordar o contexto regional em que o objeto de nossa exposição se insere. O maior desafio da pós-graduação na Região Norte não tem sido as distâncias colossais que marcam o território e dificultam mais detalhada identificação e análise de seus problemas de pesquisa. O maior desafio está em corrigir as assimetrias regionais no desenvolvimento científico e tecnológico em relação ao contexto nacional. Pensar e implementar políticas capazes de conduzir o País para um novo patamar de desenvolvimento científico e tecnológico ao longo da próxima década constitui o entendimento basilar acerca das ações indispensáveis com vistas à inclusão da Região Norte nos projetos nacionais de desenvolvimento da ciência e, especificamente, da pós-graduação brasileira.

A Carta de Boa Vista (manifesto nascido no Fórum de PróReitores de Pesquisa e Pós-Graduação das Instituições de Ensino Superior da Região Norte - Foprop Norte -, reunido em Boa Vista, RR) indica que a superação das assimetrias regionais no desenvolvimento científico e tecnológico do Brasil permanece um dos maiores desafios nacionais, o que exige, para a próxima década, políticas públicas ainda mais ousadas. As instituições de ensino superior da Região Norte foram palco de um esforço realizado nos últimos anos com vistas à redução de tais assimetrias, por governos, instituições e grupos de pesquisa, com resultados expressivos que impediram um maior distanciamento entre as regiões, no momento em que a ciência brasileira deu saltos extraordinários. Entretanto, ainda há muito a ser superado.

A criação de novas universidades e campino Amazonas constitui exemplo dos avanços alcançados nos últimos anos. Em 2001, a criação da Universidade do Estado do Amazonas (UEA) significou um salto bastante expressivo na oferta de vagas no ensino superior. Atualmente, a referida instituição apresenta um quadro de cerca de 22.000 alunos no 
ensino de graduação. Ao ser instituído, em 2008, o Instituto Federal de Educação, Ciência e Tecnologia do Amazonas (Ifam) também aumentou a oferta de cursos superiores no estado. A criação de cinco novos campida Universidade Federal do Amazonas nas cidades de Benjamin Constant, Humaitá, Coari, Itacoatiara e Parintins fez com que a referida instituição se tornasse a Ifes que mais se expandiu proporcionalmente no Brasil no que diz respeito à interiorização das universidades, chegando a 2011 com 25.000 alunos de graduação. Isso pode ser verificado nos Quadros 1 e 2, pela observação da evolução do número de docentes efetivos de Ifes no Brasil e na Região Norte, em especial.

Quadro 1. Evolução do número de docentes efetivos de Ifes, por região geográfica, entre 2002 e 2012

\begin{tabular}{l|c|c|c|c|c|c|c|c|c|c|c}
\hline \multicolumn{1}{c|}{ Região } & $\mathbf{2 0 0 2}$ & $\mathbf{2 0 0 3}$ & $\mathbf{2 0 0 4}$ & $\mathbf{2 0 0 5}$ & $\mathbf{2 0 0 6}$ & $\mathbf{2 0 0 7}$ & $\mathbf{2 0 0 8}$ & $\mathbf{2 0 0 9}$ & $\mathbf{2 0 1 0}$ & $\mathbf{2 0 1 1}$ & $\mathbf{2 0 1 2}$ \\
\hline Sudeste & 14.714 & 14.226 & 14.302 & 14.428 & 15.703 & 15.776 & 16.436 & 18.836 & 21.350 & 22.256 & 22.256 \\
\hline Nordeste & 11.805 & 11.240 & 11.511 & 11.687 & 12.761 & 12.850 & 14.018 & 16.361 & 18.156 & 18.893 & 18.891 \\
\hline Sul & 8.100 & 7.687 & 7.708 & 7.815 & 8.249 & 8.339 & 8.715 & 9.515 & 10.792 & 11.489 & 11.497 \\
\hline C-Oeste & 4.246 & 4.083 & 4.108 & 4.233 & 4.742 & 4.698 & 5.228 & 6.243 & 6.982 & 7.251 & 7.257 \\
\hline Norte & 3.465 & 3.587 & 3.829 & 4.055 & 4.543 & 4.540 & 4.876 & 5.684 & 6.392 & 6.731 & 6.733 \\
\hline Total & 42.330 & 40.823 & 41.458 & 42.218 & 45.998 & 46.203 & 49.273 & 56.639 & 63.672 & 66.620 & 66.634 \\
\hline
\end{tabular}

Fonte: MEC-MPOG-2013

Quadro 2. Evolução do número de docentes efetivos de Ifes da Região Norte, entre 2002 e 2012

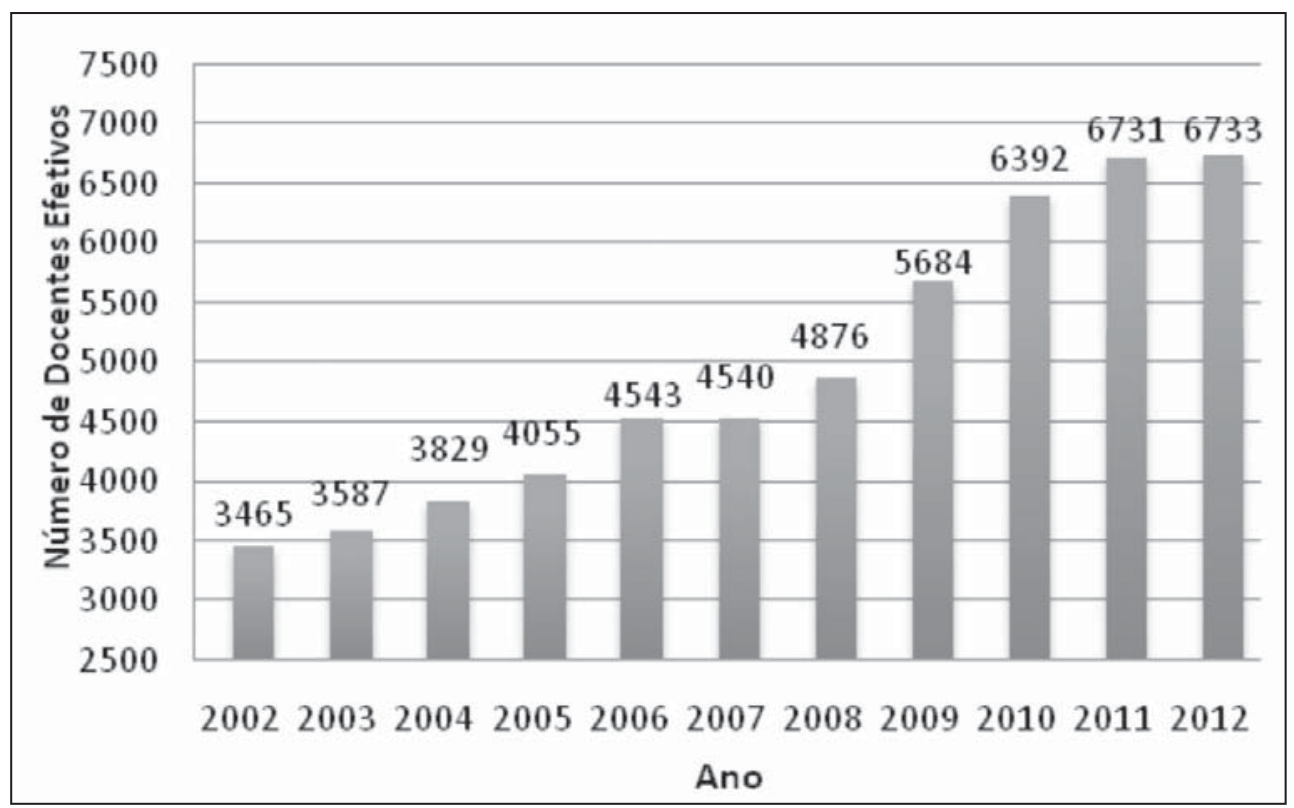

Fonte: MEC-MPOG-2013. 
Na pós-graduação os avanços também foram significativos. Para se ter uma ideia da importância, somente na Ufam, dos atuais 35 programas de pós-graduação, 25 foram criados entre 2000 e 2010, sendo nove cursos de doutorado de um total de 14. Esses números espelham a velocidade com que a pós-graduação vem se ampliando na região. Isto foi possível, entre outros fatores, pela incorporação de algumas centenas de doutores às instituições regionais. Entretanto, como expressa o Quadro 3, em relação às demais regiões do País, mesmo reconhecendo que no Norte há uma menor densidade demográfica, a pós-graduação ainda tem muito espaço para crescer.

Quadro 3. Número de cursos de pós-graduação reconhecidos pela Capes

\begin{tabular}{lcccccc}
\hline \multirow{2}{*}{$\begin{array}{c}\text { Região } \\
\text { Geográfica }\end{array}$} & \multicolumn{2}{c}{ Mestrado * } & \multicolumn{2}{c}{ Doutorado } & \multicolumn{2}{c}{ Total } \\
\cline { 2 - 7 } & $\mathbf{N}^{\circ}$ & $\%$ & $\mathbf{N}^{\circ}$ & \multicolumn{1}{l}{$\%$} & $\mathbf{N}^{\circ}$ & \multicolumn{1}{l}{$\%$} \\
\hline Sudeste & 1336 & $\mathbf{4 6 . 5 \%}$ & 947 & $55.8 \%$ & 2283 & $50.0 \%$ \\
\hline Sul & 590 & $20.6 \%$ & 336 & $19.8 \%$ & 926 & $20.3 \%$ \\
\hline Nordeste & 562 & $19.6 \%$ & 252 & $14.9 \%$ & 814 & $17.8 \%$ \\
\hline Centro-Oeste & $\mathbf{2 3 8}$ & $\mathbf{8 . 3 \%}$ & 107 & $6.3 \%$ & 345 & $7.6 \%$ \\
\hline Norte & 145 & $5.1 \%$ & 54 & $3.2 \%$ & 199 & $4.4 \%$ \\
\hline Total & $\mathbf{2 8 7 1}$ & $\mathbf{1 0 0 \%}$ & $\mathbf{1 6 9 6}$ & $\mathbf{1 0 0 \%}$ & $\mathbf{4 5 6 7}$ & $\mathbf{1 0 0 \%}$ \\
\hline
\end{tabular}

Fonte: site da Capes - Geocapes.

*Atualizado em 31/01/2012. * Não estão incluídos os 393 cursos de mestrado profissional.

Outro elemento que se soma ao esforço da ampliação da pósgraduação na Região Norte é a criação das fundações estaduais de amparo à pesquisa, com destaque para a Fapeam, no Amazonas, e para a Fapespa, no Pará.

Esses avanços, porém, não foram suficientes para alterar substancialmente os indicadores relativos do Norte, cujas instituições continuam recebendo menos de $5 \%$ dos recursos de fomento e bolsas do Conselho Nacional de Desenvolvimento Científico e Tecnológico (CNPq), respondendo por apenas $4,4 \%$ dos cursos de pós-graduação stricto sensu e, dentre esses, apenas 3,2\% dos cursos de doutorado e $0,3 \%$ dos cursos de excelência (um único curso, na Universidade Federal do Pará, dentre os 320 avaliados pela Capes com conceito 6 ou 7). Esses indicadores refletem um problema de escassez de recursos humanos para a pesquisa científica e tecnológica na Amazônia, representando a participação da 
região com apenas 4,74\% dos doutores no País, embora $8 \%$ da população brasileira ali resida. Esse problema há muito vem sendo discutido por pesquisadores, gestores, associações científicas e governos.

São exemplos de iniciativas que cumpriram papel importante para o crescimento da pesquisa e da pós-graduação na Amazônia o Programa Novas Fronteiras, da Capes, e a Lei n $11.540 / 2007$, relativa às aplicações do Fundo Nacional de Desenvolvimento Científico e Tecnológico (FNDCT). A Carta de Boa Vista aponta que "a manutenção dessas iniciativas constitui o ponto de partida indispensável para qualquer avanço no processo de edificação de um sistema abrangente e competitivo de pesquisa e pós-graduação na Amazônia” (CARTA DE BOA VISTA, 2011). Três políticas adicionais se mostram necessárias e dizem respeito, essencialmente, a questões inter-relacionadas. São elas: a formação de recursos humanos para a pesquisa científica e tecnológica, a atração e fixação de doutores na região e a expansão do sistema de pesquisa e pós-graduação.

Uma questão ligada diretamente à proposta de abordagem sobre a elevação da qualidade da pós-graduação na Região Norte, tomando por base a Universidade Federal do Amazonas - e, evidentemente, há o uso dessa proposta para outras iniciativas de elevação da qualidade dos serviços institucionais -, tem a ver com o número elevado de docentes de IES que não possuem título de doutor. Tal situação se deve, por um lado, à ausência, no passado recente, de políticas eficazes para recrutar candidatos titulados às vagas abertas por meio de concursos públicos e, por outro lado, à quase inexistente valorização da qualificação, entre os docentes da região, dessa titulação, que recebeu maior impulso nos últimos 20 anos. Modificar esse quadro é imprescindivel para dotar a região de recursos humanos para a pesquisa científica e tecnológica. E mudar esse quadro significa igualmente dotar os programas com a qualidade necessária para as demandas locais de formação.

Essa questão se liga também a algumas ações fundamentais que devem ser levadas em conta no contexto da elevação da qualidade dos cursos de pós-graduação de que falamos. A título de exemplo, considera-se fundamental a oferta de um número muito maior de 
doutorados interinstitucionais (Dinter), com a perspectiva da redução de assimetrias regionais; a concessão de bolsas de pelo menos três anos aos docentes que buscam a qualificação em instituições de outras regiões do País (com ou sem estágio no exterior) e do exterior; o fim do impedimento legal de qualificação docente durante o estágio probatório; além da indução da abertura de doutorados em áreas estratégicas para o desenvolvimento regional; entre outros.

Todo esforço que puder ser feito para formar pesquisadores da e na Amazônia - ação primordial dos cursos de pós-graduação - e para a elevação da qualidade das iniciativas de pós-graduação é urgente para suprir a região dos recursos humanos necessários ao seu desenvolvimento econômico e social, dado o quadro que se agiganta de uma população que cresce e se modifica ainda mais com constantes fluxos migratórios, característica dos espaços amazônicos. Por ora, tem-se considerado a necessidade de associar esses esforços às políticas especificamente dirigidas à atração de doutores formados ou residentes em outras regiões e em outros países (CARTA DE BOA VISTA, 2011). A atração e fixação de doutores serão possíveis com a adoção de políticas que sinalizem a real oportunidade de uma carreira científica bem-sucedida na Amazônia, especificamente no Estado do Amazonas, e a garantia de permanente interação com os centros de pesquisa concentrados em outras regiões do País e do exterior. Uma das formas de apoio pensada é a "concessão de Bolsas de Produtividade em Pesquisa e Bolsas de Produtividade em Desenvolvimento Tecnológico e Extensão Inovadora com taxa de bancada (Grant) a todos os doutores com projetos aprovados quanto ao mérito, pelo prazo mínimo de quatro anos" (Ibidem, p. 2, grifo dos autores).

Além das proposições acima citadas, destaca-se a necessidade do apoio financeiro das Fundações de Amparo à Pesquisa (FAPs) estaduais para a infraestrutura de pesquisa; a concessão de Bolsas de Professor Visitante Nacional Sênior para atuação em todos os campide IES (não apenas para os campi ou instituições mais jovens). "Políticas adicionais precisam ser formuladas para a atração de pesquisadores estrangeiros bem qualificados e interessados nos temas amazônicos" (CARTA DE BOA VISTA, 2011, p. 2, grifo dos autores). Vislumbra-se a 
disponibilidade de candidatos estrangeiros com esse perfil no ambiente acadêmico internacional; entretanto, essa disponibilidade latente tem sido pouco ou nada aproveitada pelas instituições de ensino superior da Região Norte (IES-N) em razão da ausência dos instrumentos que tornem as oportunidades locais atrativas.

O rompimento com o ciclo de dependência dos centros mais desenvolvidos na formação de recursos humanos depende fortemente da efetividade das políticas de qualificação e atração de doutores para atuarem no Amazonas. A expansão do sistema de pós-graduação da região é indispensável, mas também requer ações específicas adicionais, dentre as quais destacamos: a criação de um programa especial de apoio à infraestrutura de pesquisa nas IES-N. O documento de Boa Vista destaca que na Região Norte não se trata apenas de atualizar a infraestrutura existente, mas, muito frequentemente, também de criar as condições iniciais para a pesquisa em muitas áreas do conhecimento. Outro esforço precisa ser empreendido para incrementar fortemente a iniciação científica, pois ela é potencialmente um grande instrumento na qualificação dos candidatos aos cursos de mestrado e doutorado. A intensificação do intercâmbio com os programas consolidados no País e no exterior também é apontada como fator importante para estimular a consolidação da pós-graduação na região. Há ainda a necessidade de fomentar a realização de estágio pós-doutoral pelos docentes; a introdução na matriz orçamentária das instituições de ensino superior de verbas e de vagas para docentes e técnicos, especificamente destinadas à indução da criação de novos programas de pós-graduação; e a contratação de pessoal para o apoio técnico à pesquisa científica, entre outros aspectos.

As preocupações que norteiam a Carta de Boa Vista têm como horizonte a meta de triplicar o número de doutores na Amazônia até2020. Embora essa meta seja insuficiente para garantir um perfilhamento com os indicadores nacionais, será possível uma aproximação considerável. O cumprimento dessa meta depende do necessário crescimento do sistema de pós-graduação, de modo a alimentar os ciclos seguintes de formação de recursos humanos para a pesquisa científica e tecnológica na região. 
Com certeza, o sucesso das políticas que vierem a ser executadas nas direções apontadas pelos dirigentes da pesquisa e da pósgraduação da Região Norte dependerá, sobremaneira, do conhecimento e da ponderação da realidade regional, em razão de suas distâncias geográficas, da diversidade de seus ambientes culturais e naturais, da peculiaridade de seus desafios e da heterogeneidade de suas instituições, daí também a necessidade da interlocução intensa com os atores locais.

O conjunto das diretrizes apontadas pelo Foprop - Norte merece atenção não apenas pelo que pode representar para as instituições da região amazônica, mas, sobretudo, pela relevância para o País, com vistas a um projeto de desenvolvimento baseado na conservação e no aproveitamento sustentável de suas mais expressivas riquezas naturais, para a extensão das conquistas econômicas, sociais, do conhecimento e da cultura às populações que ocupam mais da metade do território nacional.

Verifica-se, dessa forma, uma complexidade bastante específica no contexto da pós-graduação na Região Norte, um espaço geográfico historicamente preterido que requer simultaneamente ações de formação em nível de pós-graduação e a aplicação de políticas de qualificação capazes de, associadas às especificidades regionais, elevar a performance dos serviços que socialmente as IES têm.

\section{Programa de Apoio à Consolidação e ao Avanço da Qualidade da Pós- Graduação da Universidade Federal do Amazonas - PACPG/Ufam: uma proposta de gestão da pós-graduação}

Historicamente, a universidade tem uma missão a cumprir com a sociedade. A definição dessa missão constitui o próprio ideal de instituição que desejamos como profissionais e cidadãos. Esse trabalho social há muito precisa ocorrer na Região Norte, especificamente no Amazonas, de forma mais incisiva e com notável qualidade de serviços.

Criar uma cultura institucional nas instituições que favoreça a constante oferta de qualidade parece ser o desafio da excelência. 
Se a cultura pode ser definida como a base de um povo, como os procedimentos dos fazeres dos indivíduos na vida em comum, então a cultura institucional se fundamenta nos procedimentos institucionais com vistas aos resultados intimamente ligados à missão social que a universidade precisa assumir.

Falando de cultura de um modo geral, Canclini (2008) diz que elas estão hoje em mudança, sofrem alterações desencadeadas por agentes diversos; elas se organizam hibridamente no que diz respeito aos procedimentos. Isso significa dizer que as culturas têm se interrelacionado mais rapidamente como consequência de um ideal que não mais se restringe às etnias ou aos espaços. Institucionalmente, isso se dá na busca, no caso da universidade, pela qualidade dos serviços já alcançados em outros centros de outras regiões no País ou fora dele. Canclini (2008) afirma que houve uma quebra no domínio do que chama de coleções organizadas pelos sistemas culturais: os fazeres pertencem às culturas, não mais a uma só. Há, então, uma ruptura no que diz respeito aos patrimônios culturais dos povos. Assevera ainda que os tais três processos aos quais nos referimos são decisivamente determinantes de uma engenharia cultural que rompe fronteiras internacionais, nacionais e locais.

\footnotetext{
Passamos de sociedades dispersas em milhares de comunidades rurais com culturas tradicionais, locais e homogêneas, em algumas regiões com fortes raízes indígenas, com pouca comunicação com o resto de cada nação, a uma trama majoritariamente urbana, em que se dispõe de uma oferta simbólica heterogênea, renovada por uma constante interação do local com redes nacionais e transnacionais de comunicação (CANCLINI, 2008, p.285).
}

Não seria estranho imaginar que esse movimento também opera no nível das instituições. Assim, vemos uma inserção bastante apropriada para o PACPG/Ufam, que, em linhas gerais, estabeleceu como meta a conquista da excelência acadêmica da pós-graduação da Universidade Federal do Amazonas, uma expressão do ensino superior na Região Norte.

O PACPG/Ufam é um programa institucional composto por vários projetos adotados a partir de 2013 em todos os PPGs da instituição. Visa 
à consolidação da pós-graduação stricto sensu da Ufam com a melhoria dos conceitos Capes dos programas de pós-graduação ao longo de três períodos de avaliação, entre 2013 e 2021. Espera-se, com a implantação do PACPG/Ufam, que, no primeiro triênio de avaliação (2013-2015), não menos de 50\% dos PPGs da Ufam subam seus conceitos Capes. 0 padrão, portanto, é o conceito Capes, base para o País. Em associação a esse esforço de busca de qualidade, planeja-se também a criação de 12 cursos de doutorado nos próximos três anos, o que representará o dobro dos atualmente existentes na Ufam.

O início das atividades de pós-graduação na Ufam data de 1984, com a criação do Programa de Pós-Graduação em Ciências dos Alimentos. Ainda na década de 1980, mais dois programas de pósgraduação foram criados e iniciaram suas atividades em Química e em Educação, que datam de 1985 e 1987, respectivamente.

Na década de 1990, seis PPGs foram criados, representando um crescimento de $100 \%$ da pós-graduação da Ufam no que concerne ao número de PPGs relativamente àqueles existentes na década anterior.

Entre o ano 2000 e os dias atuais, 29 PPGs foram aprovados pela Capes e iniciaram suas atividades na instituição. Isso representa um crescimento superior a $220 \%$ do número de PPGs em funcionamento no final da década de 1990. É de fácil percepção o enorme esforço realizado pela instituição, seus docentes, técnicos administrativos em educação, discentes e dirigentes na busca do crescimento quantitativo da pósgraduação e da pesquisa na Ufam.

Nesta última década, a pós-graduação na Ufam manteve o ritmo do crescimento quantitativo do número de PPGs na instituição e ainda foi capaz de levar ao interior do estado o primeiro PPG da história do Amazonas: o Programa de Pós-Graduação em Ciência e Tecnologia para Recursos Amazônicos, do Instituto de Ciências Exatas e Tecnologia de Itacoatiara.

Embora esses avanços tenham sido significativos, ainda é fundamental atribuir qualidade aos programas. Toda ação deflagrada pela linha PACPG significa a adoção de um novo paradigma nessa história recente da pós-graduação. 
O PACPG-Ufam é expresso em um documento executivo elaborado pela Pró-Reitoria de Pesquisa e Pós-Graduação e aprovado pela Administração Superior da Ufam, construído a partir das informações e dos dados contidos nos documentos de avaliação da Capes.

No processo da sua implantação, os PPGs definirão as diretrizes e metas que levarão os programas ao aumento dos conceitos junto à Capes. Os indicadores propostos pelos PPGs serão instrumentos de acompanhamento e orientação de uma comissão composta por consultores externos e internos de renomada/reconhecida experiência em pós-graduação.

Passaremos, a seguir, a expor as ações do programa.

\section{Projetos de acompanhamento e orientação dos programas de pós- graduação e de reconhecimento acadêmico dos docentes e discentes da Ufam}

O projeto de acompanhamento e orientação dos programas de pós-graduação da Ufam é o principal do PACPG da instituição. Ele é caracterizado por possuir um programa de metas factíveis para o crescimento do conceito Capes em cada PPG. A coordenação do PPG elabora um diagnóstico (banco de dados) dos últimos seis anos que explique o desenvolvimento do PPG e, a partir desse diagnóstico, estabelece as metas que levem o programa a um crescimento de pelo menos um conceito (de 3 para 4 ou de 4 para 5) na avaliação da Capes em 2016.

Para tanto, são criadas as Comissões de Acompanhamento do Programa (CAPs), que têm a missão precípua de acompanhar as metas estabelecidas pelo PPG e orientá-lo na direção do aumento do conceito Capes, já no triênio 2013-2015. A CAP será constituída de dois consultores sêniores, de elevada experiência em gestão de PPG ou de pró-reitoria e com participação atual ou passada em comissões de avaliação da Capes. Adicionalmente, haverá um membro interno, docente da Ufam, mas não necessariamente do PPG que a CAP acompanhará ao longo dos próximos três anos. 
As CAPs se reportarão diretamente ao comitê executivo do PACPG/Ufam enviando relatórios de visitas de acompanhamento. Os relatórios contêm:

a) A análise do diagnóstico (banco de dados) elaborado pelo coordenador do programa;

b) A viabilidade da proposta do PPG para o crescimento de um ponto no conceito Capes, em 2016;

c) As necessidades mínimas do PPG a serem atendidas pela administração superior para o saneamento das necessidades básicas do programa; e

d) Outras demandas emanadas pelo comitê executivo.

O projeto de reconhecimento acadêmico dos docentes e discentes da Ufam tem a finalidade de institucionalizar o reconhecimento dos talentos da universidade, via um evento anual solene de premiação dos docentes e discentes da Ufam que se destacam no mundo acadêmico, sobretudo no fortalecimento da pesquisa e da pós-graduação.

O Prêmio Ufam de Mérito Acadêmico será concedido anualmente pela administração superior da Universidade Federal do Amazonas aos docentes e discentes que reunirem, em suas atividades de produção científica, cultural e artística, características de alta qualidade e originalidade. A avaliação focará os trabalhos produzidos nos dois anos civis imediatamente anteriores à edição do prêmio.

O Prêmio Ufam de Mérito Acadêmico receberá o nome de um cientista ilustre, brasileiro ou radicado no Brasil, que tenha desenvolvido suas atividades científicas, culturais ou artísticas na Ufam. Os docentes indicados ao Prêmio Ufam de Mérito Acadêmico necessariamente devem pertencer ao quadro de servidores da universidade, e os discentes indicados deverão ser alunos regulares dos programas de graduação, do Programa Institucional de Bolsa de Iniciação Científica (Pibic) ou do Programa Institucional de Iniciação à Docência (Pibid). Eles serão selecionados em cada uma das grandes áreas do conhecimento:

- Ciências Agrárias, Ciências Biológicas e Ciências da Saúde;

- Ciências Humanas, Ciências Sociais Aplicadas, Linguística, Letras e Artes; e

- Ciências Exatas e da Terra e Engenharias e Computação. 
Com a criação do Prêmio Ufam de Mérito Acadêmico, a instituição está demonstrando apreço, respeito e reconhecimento aos seus docentes e discentes comprometidos com as atividades de produção científica, cultural e artística de alto nível. Corroborará com o projeto de inserção da Ufam no meio acadêmico e científico nacional e, ao mesmo tempo, promoverá a publicização dos talentos acadêmicos da instituição para toda a sociedade amazonense, via os meios midiáticos locais e nacionais, como forma de tornar mais transparentes os investimentos públicos feitos na universidade.

\section{Projeto de inserção da Ufam no meio acadêmico e científico nacional}

A história da pós-graduação na Universidade Federal do Amazonas é relativamente recente, muito embora a instituição tenha seu marco de criação em 17 de janeiro de 1909. Ao longo de mais de 100 anos, a Ufam conquistou espaço e credibilidade na sociedade amazonense, assumindo um papel fundamental em relação à formação técnica e cidadã de profissionais - pesquisadores e cientistas - compromissados com o desenvolvimento sustentável da Amazônia. Pode-se dizer que esse histórico de pós-graduação da Ufam tem ligação umbilical com o histórico da pós-graduação no Instituto Nacional de Pesquisas da Amazônia (Inpa). Segundo Val (2000):

Desde a década de 1970, o INPA, em parceria com a Universidade Federal do Amazonas, tem procurado, por meio dos cursos de pós-graduação, acompanhar os reclames da sociedade em geral e atender às demandas de maior conhecimento. Assim, tem formado recursos humanos aptos a estudar a biodiversidade da Amazônia, inventariando e qualificando sua flora e fauna, registrando sua abundância e ocorrência, referenciando geograficamente seus componentes e estudando processos e produtos para recomendar ações que viabilizem, em última instância, o uso sustentável desta biodiversidade (p. 4).

A criação de cursos de pós-graduação oferecidos pelo convênio Inpa-Ufam constituiu, segundo a autora, um passo significativo no caminho da formação de profissionais qualificados no desenvolvimento de projetos que gerassem conhecimento sobre a Amazônia. Atualmente, 
a Ufam recebe da comunidade científica local reconhecimento por sua crescente atuação e importância na formação de recursos humanos altamente qualificados, em especial em nível de pós-graduação. Isso ocorre graças à junção do esforço institucional ao empenho da comunidade universitária. Entretanto, tal situação não reflete a participação de seus docentes/pesquisadores no meio acadêmico científico nacional, principalmente em esferas de decisão dos diversos comitês técnico-científicos das agências de ciência e tecnologia existentes no País.

As cooperações interuniversitárias nacionais estabelecidas com programas de pós-graduação consolidados no Brasil e a aproximação com grupos de pesquisadores mais amadurecidos e com as sociedades científicas brasileiras ainda são insuficientes para fazer transparecer a real importância da produção científica construída ao longo dos anos na Ufam. Desta feita, o PACPG/Ufam deverá atuar de forma intensa e propositiva para dar melhor visibilidade e participação a seus docentes / pesquisadores no cenário nacional por intermédio do projeto de inserção da Ufam no meio acadêmico e científico nacional.

Para alcançar tal propósito, serão instituídas atividades de rotina em busca da aproximação com personalidades e grupos de pesquisadores renomados da ciência brasileira. Ter-se-á particular atenção com o propósito de inserir a Ufam em escola(s) de altos estudos em todas as áreas do conhecimento.

\section{Considerações finais}

A título de conclusão, podemos dizer que o tema da elevação da qualidade da pós-graduação na Região Norte do Brasil, em especial no estado do Amazonas, apresenta inúmeros desafios quando se fala da atuação das universidades públicas. Verificamos que a questão da qualidade da pós-graduação acha-se intimamente ligada à compreensão da identidade da Ufam como instituição federal de ensino superior no contexto continental da Amazônia brasileira, com sua reserva florestal de proporções superlativas, seus rios, suas estradas, seu povo da floresta, 
que inicialmente se amalgamou ao colonizador europeu, ao africano e ao brasileiro nordestino em séculos de ação exploratória; gente que regula a vida pelo ciclo das águas, quer fluviais, quer pluviais, e cuja cultura se acha embrenhada na mata - cultura refletida no comer, no fazer e no ser.

Consideramos fundamental que sejam estabelecidas por todas as instituições amazônidas, sobretudo aquelas vinculadas à formação, ações cuidadosas que levem em conta os aspectos sociais, políticos e culturais do homem da região, ironicamente conhecidos pelo estrangeiro, mas desconhecidos por seus compatriotas. A Amazônia experimentou décadas de povoamento ordenado por políticas de ocupação alienadas de seu povo e hoje detém, configurado em suas universidades públicas, um polo de produção de conhecimento bastante expressivo, que tem contribuído, apesar de tudo, para a consolidação da pesquisa no Brasil.

É possível dizer ainda que os programas de elevação de qualidade da pós-graduação devem ser implementados não apenas porque a região guarda abissais diferenças em relação a outros centros do País, mas, sobretudo, devido a sua riqueza natural, que deveria estar muito mais integrada aos interesses científicos brasileiros, em uma dinâmica de excelência plenamente possível em nosso tempo.

A ciência brasileira, em termos qualitativos, vem avançando de forma notável nas últimas décadas. Todavia, o estado do Amazonas ainda se acha em busca da consolidação dos padrões estabelecidos. Mais do que implementar ações que assegurem a elevação da qualidade da oferta de pós-graduação pelas universidades, constitui algo fundamental para a região e para o estado a instauração de uma cultura institucional decorrente de natureza análoga à iniciativa aqui tratada. Essa elevação da qualidade fortalecerá a estrutura das IES Iocais, ampliará suas relações com outras universidades brasileiras e tornará mais dinâmico o diálogo com instituições de fora, assegurando sua presença no cenário internacional, o que já pode ser verificado em alguns campos do conhecimento pela atuação de uns poucos cientistas da região nas principais instituições internacionais de ciência, considerando que cientistas do mundo inteiro têm altíssimo interesse em pesquisar 
a Amazônia, embora alguns grupos, talvez pela inexistência de um ordenamento nas ações de pesquisa, nem sempre venham agindo em sintonia com os interesses da ciência nacional.

A garantia da ampliação de direitos e da democratização do acesso a todos os níveis de ensino no Brasil com qualidade, com certeza, requer políticas de Estado, sobretudo políticas voltadas para as regiões menos desenvolvidas do território nacional. No estado do Amazonas, atravessar mais uma década sem resolver problemas pontuais da pósgraduação significaria comprometer sua incorporação ao processo de desenvolvimento em curso no País e, também, comprometer projetos nacionais diretamente dependentes de conhecimento da Amazônia, de suas riquezas e viabilidades para impulsionar o ambiente científico nacional.

Recebido em 31/05/2013

Aprovado em 17/03/2014

\section{Referências bibliográficas}

CANCLINI, N. G. Culturas híbridas: estratégias para entrar e sair da modernidade. Trad. Heloísa Pezza Cintrão, Ana Regina Lessa. 4 ed. São Paulo: Ed. da Universidade de São Paulo, 2008.

CARTA DE BOA VISTA. Documento do Fórum de Pró-Reitores de Pesquisa e Pós-Graduação das Instituições Públicas de Ensino Superior da Região Norte do Brasil. 2011.

FERRETI, C. J.; SILVA JR., J. dos R. 0 institucional, a organização e a cultura da escola. Prefácio de Newton Duarte. São Paulo: Xamã. 2004.

CAPES - Coordenação de Aperfeiçoamento de Pessoal de Nivel Superior. Geocapes, Disponivel em: www.capes.gov.br. Acesso em: 30 jan. 2012.

VAL, V. M. F. de A. (Org.). Um pouco da nossa história - 30 anos de pós-graduação na Amazônia. Manaus: INPA/Ufam/Capes/CNPq, 2000. 